\title{
Spinal Cystic Schwannoma: A Rare Case Report
}

\begin{abstract}
Das $\mathrm{S}^{1}$, Khan $\mathrm{AH}^{2}$, Sarker $A C^{3}$, Ghosh $\mathrm{D}^{4}$
Conflict of interest: There is no conflict of interest relevant to this paper to disclose.

Funding Agency : was not funded by any institute or any group.

Contribution of Authors : Principal Investigator- Dr. Sukriti Das

Manuscript preparation- Professor Dr. Akhlaque Hossain Khan

Data collection- Professor Dr. Asit Chandra Sarker

Editorial formatting- Dr. Dipankar Ghosh

Copyright: @2020bang.BJNS published

Abstract

Spinal cystic Schwannomas are very rare tumors and have been reported in only a few case reports in literature. Our case, Mrs. Halima, a 48-year-old female was admitted in Neurosurgery department of Dhaka Medical College Hospital with the complaints of low back pain more at night occasionally radiating to right buttock and numbness and tingling of the right lower limb for 2 years. MRI of Lumbo-sacral spine revealed a large circumscribed and well delineated intradural extramedullary space occupying lesion of iso to hypointense appearance in $T_{1}$ WI with ring enhancement on administration of gadolinium. Per-operative observation and post-operative histopathological examination revealed schwannoma. Contrast enhanced MRI was very important for the diagnosis of this rare type of tumor and surgical planning. Surgical removal was complete and patient was recovered uneventfully.
\end{abstract} by BSNS. This article is published under the creative commons CC-BY-NC license. This license permits use distribution (https://creativecommons. orgf/licences/by-nc/4-0/)reproduction in any medium, provided the original work is properly cited and is not used for commercial purposes.

Received: 10.09 .2020

Accepted: 12.11 .2020
Key Words: Cystic schwannoma, Magnetic Resonance Imaging, Intraduralextramedullary.

Bang. J Neurosurgery 2021; 10(2): 223-225

\section{Introduction}

Spinal schwannomas are benign tumors arising from the spinal nerve root sheaths and are the commonest intradural extramedullary spinal tumors ${ }^{1}$. Schwannomas are mostly solid or heterogeneously solid tumors. Though cystic changes in solid schwannomas are well described, predominantly cystic schwannomas are uncommon ${ }^{4,5}$. Differentiating these cystic lesions from similar cystic lesions in the intradural extramedullary space is important, and Magnetic Resonance Imaging (MRI) plays a vital role in this context.

\section{Case Report:}

A 48-year-old female was admitted in the Neurosurgery Department of Dhaka Medical College Hospital with complaints of numbness and tingling of the right lower limb for 2 years. She also complained of low back pain more at night occasionally radiating to right buttock with mild difficulty in walking for same duration. She did not give any history of trauma, fever, night sweats, cough, hemoptysis, chest pain, melena etc. On examination, she was found mid-aged female with average body built, non-anemic, anicteric and all the vital signs were within normal limit. On lower limbs examination, she had motor weakness in right lower limbs (MRC grade $4+/ 5$ at the knee and ankle), decreased sensations below the level of L2 dermatome. No abnormal deep tendon reflexes or pathological reflexes were found to be exist. The spinal radiographs revealed no endplate destruction, enlargement of spinal canal, or deformity of spinal structures. MRI of the lumbar spine revealed an intradural cystic mass occupying the L2-L4 space, which appeared the iso to hypointense appearance in $\mathrm{T}_{1} \mathrm{WI}$ with hyperintensity in $\mathrm{T}_{2} \mathrm{WI}$. The adjacent cauda equina were displaced by the lesion. After intravenous

1. Dr. Sukriti Das, Associate Professor, Department of Neurosurgery, Bangabandhu Sheikh Mujib Medical University.

2. Professor Dr. Akhlaque Hossain Khan, Professor, Department of Neurosurgery, Bangabandhu Sheikh Mujib Medical University.

3. Professor Dr. Asit Chandra Sarker, Head- Department of Neurosurgery, Dhaka Medical college \& Hospital.

4. Dr. Dipankar Ghosh, Resident (Phase-B), Department of Neurosurgery, Dhaka Medical College \& Hospital

Address of Correspondence: Dr. Sukriti Das, MBBS, FCPS (Surgery), MS (Neurosurgery), FRCS (Edin), Associate Professor, Department of Neurosurgery, Bangabandhu Sheikh Mujib Medical University. Cell phone: +8801711676848, e-mail: sukriti66@yahoo.com. 
gadolinium administration, the cystic mass showed a marginal enhancement (ring enhancement).

The patient underwent laminectomy at $L_{2}-L_{4}$ level with total excision of the lesion. Intraoperatively, after durotomy, a cystic lesion spontaneously came out.
The cyst was decompressed and clear CSF-like fluid came out from the lesion. Then the lesion was excised maintaining the arachnoid plane. The patient had an uneventful recovery and her motor and sensory impairment improved to near normal post-operatively.

Table-I

Differential diagnosis of cystic spinal schwannomas: Analysis on MRI findings 2,4,7

\begin{tabular}{lllll}
\hline Lesion & Salient features & T1WI & T2WI & Contrast enhanced T1WI \\
\hline $\begin{array}{l}\text { Cystic } \\
\text { schwannoma }\end{array}$ & $\begin{array}{l}\text { Mostly seen in the } \\
\text { cervical and lumber spine. } \\
\text { Dorsal or lateral } \\
\text { to spinal cord. Extradural } \\
\text { extension with dumb-bell } \\
\text { appearance. }\end{array}$ & $\begin{array}{l}\text { Iso-to } \\
\text { hypointense }\end{array}$ & Hyperintense & $\begin{array}{l}\text { Intense ring } \\
\text { enhancement, } \\
\text { Irregular walls, } \\
\text { Septation. }\end{array}$ \\
$\begin{array}{l}\text { Arachnoid } \\
\text { cyst }\end{array}$ & $\begin{array}{l}\text { Mostly seen in the } \\
\text { thoracic spine. Situated } \\
\text { dorsal to cord. No } \\
\text { restriction on DWI. }\end{array}$ & $\begin{array}{l}\text { Hypointense, } \\
\text { Smooth wall }\end{array}$ & Hyperintense, & Smooth wall contrast \\
& & & & enhancement. \\
\hline
\end{tabular}

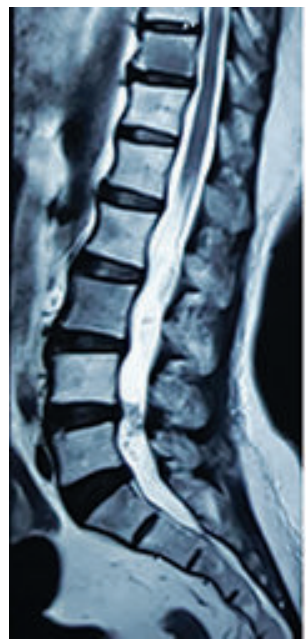

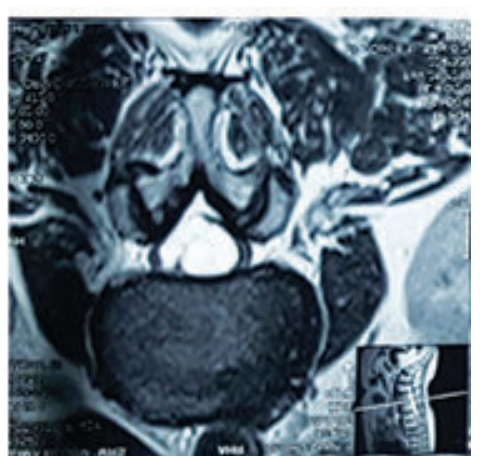

Fig.-1: Pre-operative MRI
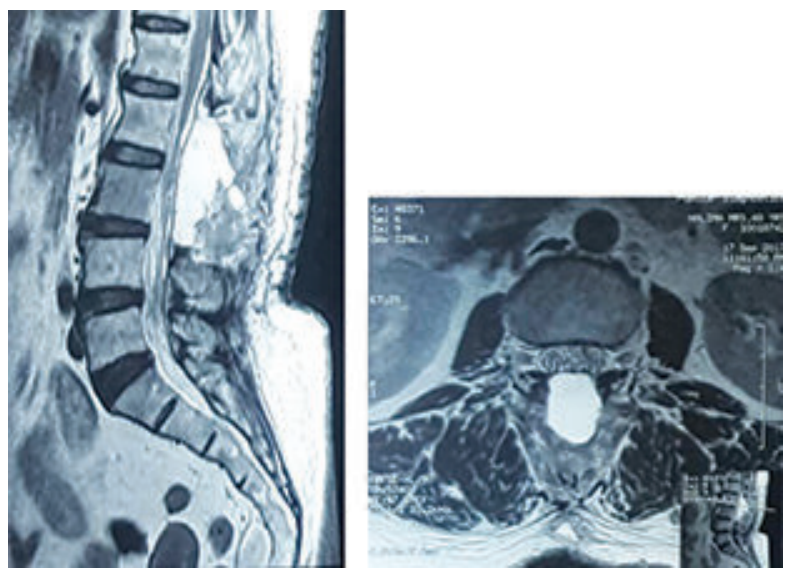

Fig.-3: Post-operative MRI

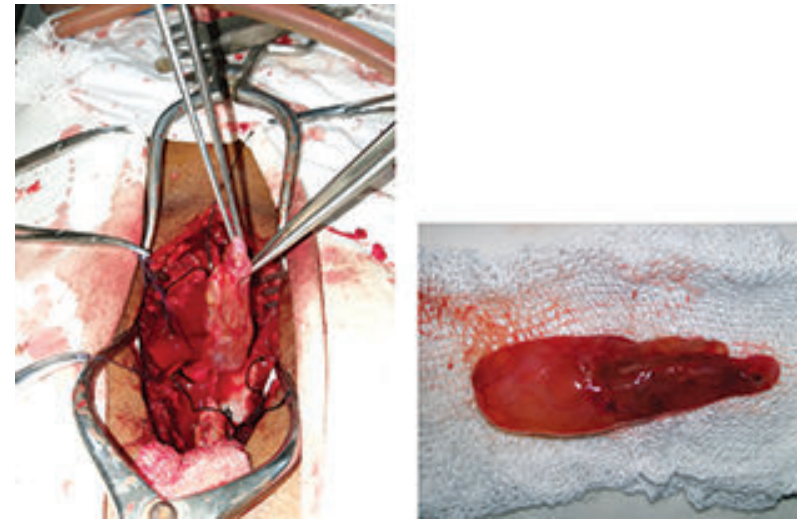

Fig.- 2: Per-operative photographs

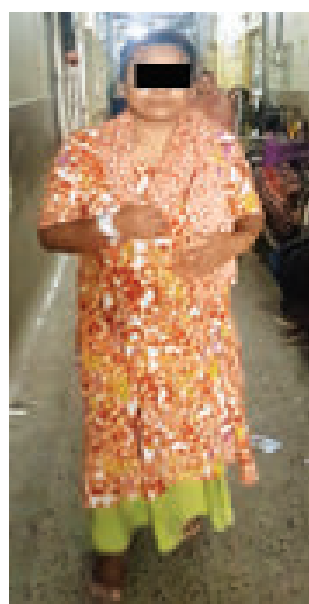

Fig.-4: Post-operative patient condition 


\section{Discussion:}

Schwannomas are the most common primary spinal cord tumors, accounting for approximately one-third of cases, usually occurring as solitary, wellcircumscribed, encapsulated, solid or heterogeneously solid, eccentrically located in intradural extramedullary space of spinal nerve roots mostly in the cervical and lumbar region ${ }^{1,6}$.

Schwannomas are usually entirely solid or heterogeneously solid tumors ${ }^{1}$. Predominantly cystic spinal schwannomas are uncommon lesions and may pose a preoperative diagnostic dilemma ${ }^{4}$. Various theories have been proposed to explain the cystic changes occurring in schwannomas. Degeneration of the Antoni B portion of a schwannoma can result in cyst formation, which may then progress to form a larger cyst ${ }^{4,5}$. This hypothesis explains the formation of totally cystic (uniloculated) schwannomas. Central ischemic necrosis/hemorrhage can be caused by tumor growth resulting in cyst formation within the tumor ${ }^{4,5}$. Another theory attributes cystic change in schwannomas to mucinous degeneration ${ }^{3,5}$. This theory may hold good for the multiloculated cystic schwannomas.

The peak incidence of spinal schwannomas is in the fourth and fifth decades of life and they do not exhibit any predilection to a particular sex. Cystic tumors have a high risk of causing progressive worsening of symptoms as a result of cyst expansion ${ }^{3}$. MRI is the preferred imaging modality for establishing diagnosis. Schwannomas generally have low-to-intermediate signal intensity on $\mathrm{T}_{1} \mathrm{Wl}$. On $\mathrm{T}_{2} \mathrm{WI}$, they may be heterogenous with focal areas of hyper-or hypointensity. Focal areas of intense hyperintensity on T2WI often correspond to cystic portions, whereas hypointensity may represent hemorrhage, dense cellularity, or collagen deposition².

The treatment of cystic schwannomas involves total excision of the lesion. Total excision is recommended because inadequate removal has a risk of recurrence. In many large series, it has been confirmed that recurrence occurred in all cases in subtotal excision ${ }^{1}$.
Hemi-laminectomy or laminectomy at the level of lesion, followed by total excision was followed in treating these lesions at our institute, and good postoperative outcome was achieved in all patients.

\section{Conclusion:}

Cystic spinal schwannomas are uncommon lesions, presenting as intradural extramedullary lesions mainly in the cervical and lumbar spine. Contrast MRI is the investigation of choice and plays a major role in predicting these lesions preoperatively. Thick irregular walls with septations, which intensely enhance on contrast injection, can accurately predict cystic multiloculated schwannomas. Uniloculated cystic schwannomas can be considered in cases of purely cystic lesions with enhancement of the thin wall. However, it is unlikely that all such cases can be predicted preoperatively on radiology. It is important to detect these lesions at surgery, as total excision is possible and almost always results in good longterm neurological outcome.

\section{References:}

1. Conti P, Pansini G, Mouchaty H, Capuano C, Conti R. Spinal neurinomas: Retrospective analysis and long-term outcome of 179 consecutively operated cases and review of the literature. Surg Neurol. 2004; 61:35-44.

2. Friedman DP, Tartaglino LM, Flanders AE. Intradural schwannomas of the spine: MR findings with emphasis on contrast-enhancement characteristics. AJR Am J Roentgenol. 1992; 158:1347-50.

3. Karatas A, Merih IS, Yildirim U, Akyuz F, Gezen F. Thoracic intradural cystic schwannoma: A case report. Turk Neurosurg. 2007; 17:193-6.

4. Parmar H, Patkar D, Gadani S, Shah J. Cystic lumbar nerve sheath tumours: MR features in five patients. Australas Radiol. 2001; 45:123-7.

5. Shiono T, Yoshikawa K, Iwasaki N. Huge lumbar spinal cystic neurinomas with unusual MR findings. AJNR Am J Neuroradiol. 1995; 16(4 Suppl):881-2.

6. Van Goethem JW, van den Hauwe L, Ozsarlak O, De Schepper AM, Parizel PM. Spinal tumors. Eur J Radiol. 2004; 50:159-76.

7. Beall DP, Googe DJ, Emery RL, Thompson DB, Campbell SE, Ly JQ, et al. Extramedullary intradural spinal tumors: A pictorial review. Curr Probl Diagn Radiol. 2007; 36:185-98. 